\title{
Characteristic of Induction Motor Drives Fed by Three Leg and Five Leg Inverters
}

\author{
Md Hairul Nizam Talib ${ }^{\dagger}$, Zulkifilie Ibrahim*, Nasrudin Abd. Rahim ${ }^{* *}$, and Ahmad Shukri Abu Hasim ${ }^{* * *}$ \\ $\dagger^{*}$ Faculty of Electrical Engineering, Universiti Teknikal Malaysia Melaka, Melaka, Malaysia \\ ${ }^{* *}$ UMPEDAC, Universiti Malaya, Kuala Lumpur, Malaysia \\ ${ }^{* * *}$ Faculty of Engineering, Universiti Pertahanan Nasional Malaysia, Kuala Lumpur, Malaysia
}

\begin{abstract}
This paper aims to compare the performance of three phase induction motor drives using Five Leg Inverter (FLI) and Three Leg Inverter (TLI) configurations. An Indirect Field Oriented Control (IFOC) method using a TLI is well established and incorporated for high performance speed drives in various industries. The FLI dual motor drive system on the other hand shows good workability in the independent control of two induction motor drives simultaneously. In this experiment, the IFOC method is utilized for both drive systems, and Space Vector Pulse Width Modulation (SVPWM) is used to generate pulses for both inverters. For the FLI, the Double Zero Sequence (DZS) Injection technique is used to generate the modulation signal. The complete experiment setup is done by using a DSpace 1103 controller board. The individual motor performances are analyzed using similar schemes, equipment setups and controller parameter values. The results show similar speed performance response capability between the single motor operation using a TLI system and the two motor operation using a FLI system based on the variable speed range either in forward or reverse operation. They also show similar load rejection abilities. However, the single motor with a TLI has a better power quality aspect such as ripple current and total harmonics distortion (THD).
\end{abstract}

Key words: Double Zero Sequence (DZS) Injection Method, Five Leg Inverter, Induction Motor Drive

\section{INTRODUCTION}

The independent control of two motor drives using a single inverter offers cost reductions by decreasing the number of power electronic switches, only one DC bus supply and one controller. In addition, it consumes less space and has lower complexity. The independent control of two three phase motors can be realized by using a Four Leg Inverter, a FLI or a Nine Switched Inverter [1]-[17]. Analysis of the FLI inverter mainly focuses on the capability of the motors to work independently with FLI performance, together with switching pattern and DC voltage utilization. This paper will thoroughly compare the individual motor performances using FLI and TLI.

Indirect FOC methods using TLIs are well established

Manuscript received May 27, 2013; revised Jul. 15, 2013

Recommended for publication by Associate Editor Sanjeet K. Dwivedi.

${ }^{\dagger}$ Corresponding Author: hairulnizam@utem.edu.my

Tel: +606-5552233, Fax: +606-5552222, UTeM

*Faculty of Electrical Engineering, Universiti Teknikal Malaysia Melaka, Malaysia

${ }^{* *}$ UMPEDAC, Universiti Malaya, Malaysia

${ }^{* * *}$ Faculty of Engineering, Universiti Pertahanan Nasional Malaysia, Malaysia and used in high performance speed drive in various industries. They are used to control one motor with three a leg inverter system. Meanwhile, a FLI two motor drives system consists of the FLI, two induction motors and separated FOC schemes for the individual motors. The system only used one five leg inverter to supply to two three phase motors. The principle of independent control for two induction motors by using a FLI voltage source inverter has been investigated in [2]-[4], [6], [12], [15]-[21]. This research focused on the operation of the carrier based or space vector based PWM modulation methods, two motor performance, switching pattern, DC utilization and total harmonic distortion (THD). Meanwhile, this study performed a direct comparison of the motor performances based on FLI and TLI systems with the same equipment, vector control scheme, motor parameters and Proportional Integral (PI) controller. The indirect field oriented control (FOC) scheme is used for the motor control drives.

Fig. 1 illustrates a block diagram of two induction motors applying the indirect FOC schemes fed by a FLI system. By referring to the control for motor M1, the torque component and the flux component of the stator, current goes through a coordinated transformation to supply the voltage amplitude, 


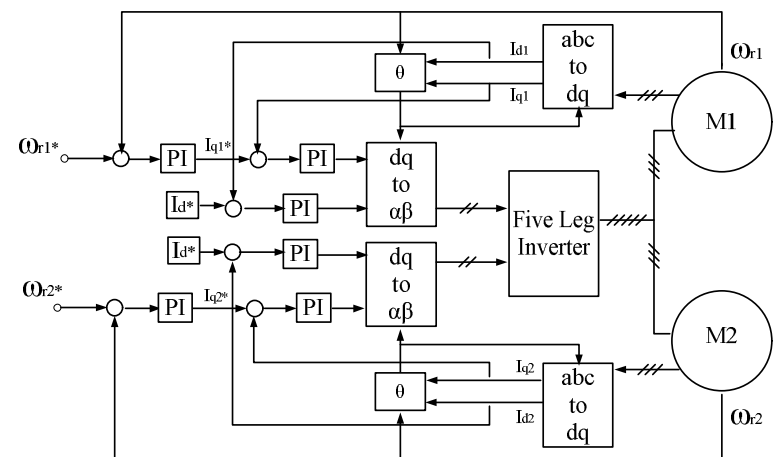

Fig.1. Two induction motor drive vector control block diagram.

phase, and frequency. The speed demand is given as the speed reference, i.e. $\omega r 1 *$ or $\omega r 2 *$ for motor M1 and motor M2, respectively. The speed demands are compared with the actual rotor speeds, $\omega r 1$ and $\omega r 2$, correspondingly. The deviation is amplified in the speed control amplifier of the PI controller and the output of the speed controller serves as the reference input to the torque current loop. The reference torque current, iq* is compared with the actual torque current component, iq and results in the torque current error. This error is processed to generate the reference voltage torque component, $\mathrm{Vq}^{*}$. On the other hand, the current flux component, $\mathrm{id}^{*}$ which was earlier set to a constant value is compared with the actual values of this variable, id. The error signal is applied to the PI controller to generate the command values of the flux voltage component, $\mathrm{Vd}^{*}$. These reference voltages are transformed to the stationary reference frame ( $\alpha \beta$ frame) using the inverse Park transformation coordinate. A similar concept is applied for the M2 control. Both signals are then synthesized using the DZS method to control the voltage supply required for the motors accordingly. Further development steps are discussed in Section II.

This experiment utilizes the FLI inverter configuration and the DZS modulation technique using the SVPWM method. The FLI SVPWM is based on the conventional TLI SVPWM with some modifications to the input signals. The individual motor performances are thoroughly compared in terms of the FLI and TLI results. This investigation focused on the variable forward speed demands, forward reverse operation, load rejection capability and total harmonic distortion (THD) of the individual motors. The contribution of this paper lies in the quantitative comparison between FLIs and TLIs for two motors and single motor operation by using similar hardware setups for both drives systems.

\section{FIVE LEG INVERTER}

\section{A. Five Leg Inverter (FLI) Configuration}

The typical connection of a five leg voltage source inverter to two three phase induction motors is shown in Fig. 2. Each of the legs consists of two switches with a total number of ten switches. Inverter legs A and B are connected to motor M1

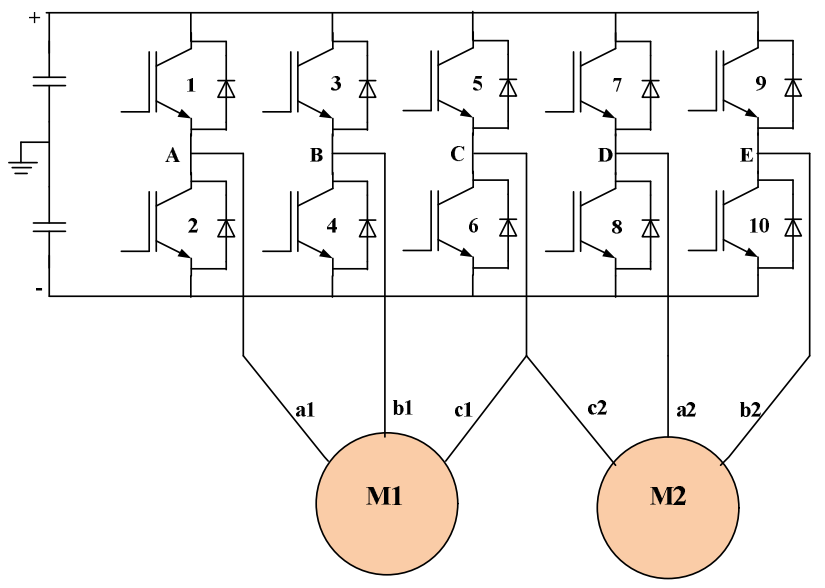

Fig. 2. Connection between five leg inverter and motors [4].

while legs D and E are connected to motor M2. In the FLI topology, one leg is used as the common leg. This common leg is shared by both motors. In this case, leg $\mathrm{C}$ is chosen as the common leg. All of the legs are connected to the three phase supply termination of the motors denoted as a1, b1, c1 and $\mathrm{a} 2, \mathrm{~b} 2, \mathrm{c} 2$ to represent motor M1 and motor M2 termination, respectively.

\section{B. Double Zero Sequence (DZS) Injection Method Configuration}

In order to control the motors in a decoupled manner, vector control is applied with an appropriate PWM method. There are numerous PWM techniques used for the FLI topology. Among these methods, as discussed in [4, 12], are Dual Voltage Modulation (DVM), the Modulation Bock Method (MBM), the Inversion Table Method (IVM) and the Double Zero Sequence Method (DZS). The DZS is the best method which enables an arbitrary distribution of the DC link voltage between two motors while maintaining its operation in constant switching frequency mode. In addition, the DZS offers less complexity and is easier to implement using standard Digital Signal Processing (DSP). This method is able to solve the drawbacks of previous PWMs such as the restriction of $50 \%$ of the DC bus voltage for one motor, asymmetrical switching frequency, underutilization of the switching state, sideband harmonics, high magnitude THD generation and their complexity problem. In addition, the DZS method is able to work using either that carrier based or SVPWM technique.

Two Arm Modulation (TAM) is another method used for FLI modulation [1], [2]. A similar connection structure is used where one of the legs is shared for the motor connection. The advantages of this method include independent control of the motors, easy implementation to a DSP and a constant switching frequency. It has similar advantages to DZS but different approaches in producing the PWM modulation signal for the FLI. 


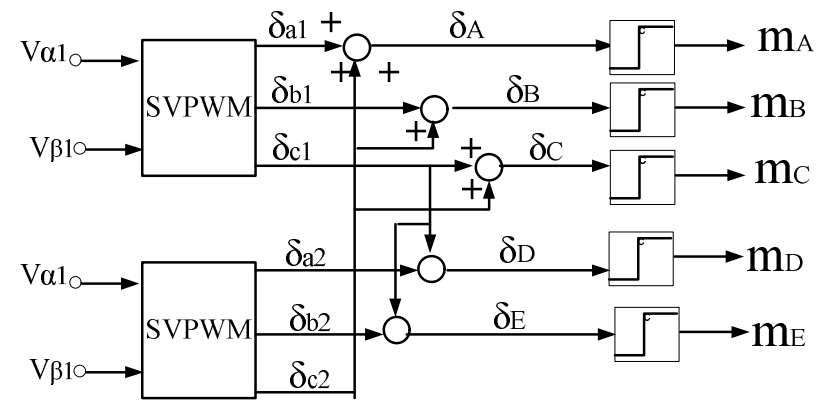

Fig. 3. Double Zero Sequence Injection Method block diagram.

A space vector DZS block diagram is shown in Fig. 3. This method utilizes standard three-phase space vector modulator to generate modulation signals for the FLI. The drawback of this method is that the total voltage requirement of the machines must not exceed the DC bus voltage. However, it is able to allocate any portion of the DC bus voltage to either of the two machines[12].

Principally, the first set of the fundamental voltages in the stationary frame is synthesized in the three-phase leg space vector modulator. This process is repeated for set 2 . The output of the modulator is $\delta$, which can be considered as the duty cycle for each of the three legs. The output signals of set 1 and set 2 are then summed in an appropriate manner to reduce the number of modulation signals from six to five as presented in the block diagram configuration. The summed results for the output of set 1 and set 2 generate the modulated signal for the FLI as shown in equation (1) below:

$$
\begin{aligned}
& \delta_{A}=\delta_{a 1}+\delta_{c 2} \\
& \delta_{B}=\delta_{b 1}+\delta_{c 2} \\
& \delta_{C}=\delta_{c 1}+\delta_{c 2} \\
& \delta_{D}=\delta_{a 2}+\delta_{c 1} \\
& \delta_{E}=\delta_{b 2}+\delta_{c 1}
\end{aligned}
$$

Finally, the modulation signals, which are denoted as $m_{A}, m_{B}$, $\mathrm{m}_{\mathrm{C}}, \mathrm{m}_{\mathrm{D}}$ and $\mathrm{m}_{\mathrm{E}}$, are generated for the FLI after comparison with the carrier signal. Based on this method, the common leg will experience a higher current due to the sum of the phase current of the two motors as well as the harmonics content. Thus the semiconductor switches need to be double the current capability for this leg if using the same motors rating and simultaneous full load current operation. However, in some specific applications such as a winder [12, 22], where the two motors never operate simultaneously with a full load current, this requirements can be tolerated. The common leg switch ratings can be determined based on the dedicated application and load forecast.

\section{EXPERIMENTAL SETUP}

A performance comparison between the TLI for single motor operation and the FLI for two motors operation are

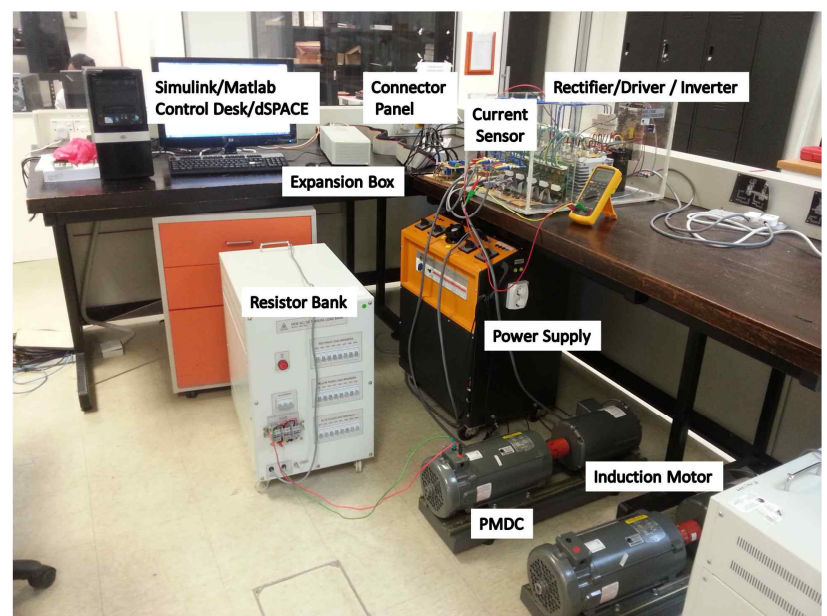

Fig. 4. The hardware experimental setup.

conducted using similar experiments setups. The experiment setup of the drive systems consists of two similar $1.5 \mathrm{~kW}$ Baldor induction motors, a $2.2 \mathrm{~kW}$ Baldor permanent magnet DC motor, a three phase rectifier module (SEMiX341D16s), a DC link capacitor $(2200 \mu \mathrm{F}, 450 \mathrm{VDC})$, an insulated bipolar transistor intelligent power module (semikron SEMiX252GB126HDs), a current sensor circuit (LEM HY-10P) with a low pass filter, an incremental optical encoder (E3-500-500-IE-H-T-B), and a Dspace 1103 DSP controller. The voltage supply is at a rated voltage of 380 Vrms and the switching frequency is $8 \mathrm{kHz}$. The sampling time is set at $50 \mu \mathrm{s}$. Tests are conducted to evaluate the performance of the motor for forward reverse no load operation and loaded operation. Fig. 4 shows the experimental setup for the TLI and FLI drive system.

\section{A. Motor Parameters}

Similar equipment is used for the TLI and FLI for single and two motor control operations. The TLI used only three of the five inverter legs. The difference lies in the pulse generating technique of the TLI and FLI. Two similar types of three-phase induction motors are used in the experiments and the details of the motor parameters are shown in Table I below.

\section{B. PI Controller}

By referring to the vector control block diagram in Fig. 1, three PI controllers are used for the speed, torque and flux control of each of the motors. Similar schemes and parameter values for the PI controllers are used in the TLI and FLI systems. The values are determined using a second order general equations method. The damping ratio, $\varsigma$ is set to 1 and the natural frequency, $\omega_{\mathrm{n}}$ is set to $100 \mathrm{~Hz}, 10 \mathrm{~Hz}$ and $1 \mathrm{~Hz}$ for the torque loop, flux loop and speed loop, respectively. An anti-wind up proportional integral controller is used in the speed control. Table II shows the PI controller parameters for the speed, torque and flux components. 
TABLE I

INDUCTION MOTOR PARAMETERS

\begin{tabular}{|l|l|}
\hline \multicolumn{1}{|c|}{ Motor Specifications } & \multicolumn{1}{c|}{ Value } \\
\hline Rated Voltage & $380 \mathrm{~V}$ \\
\hline Rated Frequency & $50 \mathrm{~Hz}$ \\
\hline Poles & 4 \\
\hline Rated Speed & $1430 \mathrm{rpm}$ \\
\hline Stator Resistance & $3.45 \Omega$ \\
\hline Rotor Resistance & $3.6141 \Omega$ \\
\hline Stator Inductance & $0.3246 \mathrm{H}$ \\
\hline Rotor Inductance & $0.3252 \mathrm{H}$ \\
\hline Magnetizing Inductance & $0.3117 \mathrm{H}$ \\
\hline Inertia & $0.02 \mathrm{kgm}{ }^{2}$ \\
\hline Viscous Friction & $0.001 \mathrm{Nm} /(\mathrm{rad} / \mathrm{s})$ \\
\hline
\end{tabular}

TABLE II

PI CONTROLLER PARAMETERS

\begin{tabular}{|l|l|}
\hline \multicolumn{1}{|c|}{ PI Controller } & Value \\
\hline Speed Controller & $\mathrm{Kp}=0.135$ \\
& $\mathrm{Ki}=0.4252$ \\
\hline Flux Controller & $\mathrm{Kp}=4.65$ \\
& $\mathrm{Ki}=8.94$ \\
\hline Torque Controller & $\mathrm{Kp}=13.43$ \\
& $\mathrm{Ki}=197.45$ \\
\hline
\end{tabular}

\section{EXPERIMENTAL RESULTS}

\section{A. Response to the Step Speed Command}

The performance of the single motor operation with a TLI and the two motor operation with a FLI are investigated at three different speed demands which are considered as high, medium and low speed under the no load condition. For this experimental setup, a three phase IM motor is coupled with a Baldor permanent magnet DC motor. An incremental optical encoder is used to measure the shaft speed which has 500 pulses per revolution. For this test, the single motor with a TLI is required to operate at 200rpm, 600rpm and 1000rpm speed steps from a standstill. A similar speed test procedure is conducted for the FLI operation where motor M1 operates at similar speed steps to those mention above and motor M2 is fixed to operate at 400rpm for all of the tests. The total maximum speed is set to operate at the rated speed as limited by the natural constrain of the FLI. Fig. 5(a) shows the responses of the three speed demand operation at 200rpm, $600 \mathrm{rpm}$ and 1000rpm for a single motor with the TLI

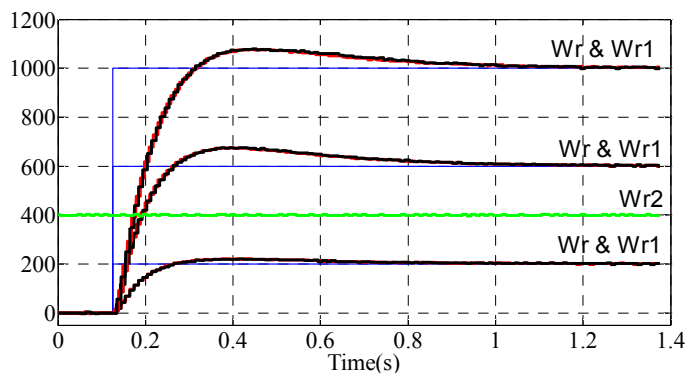

(a)

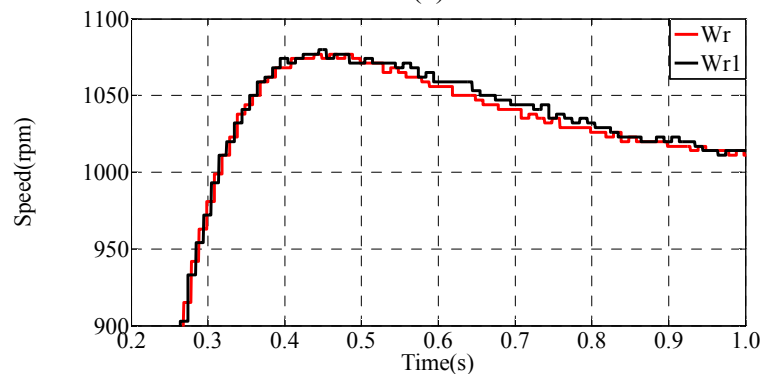

(b)

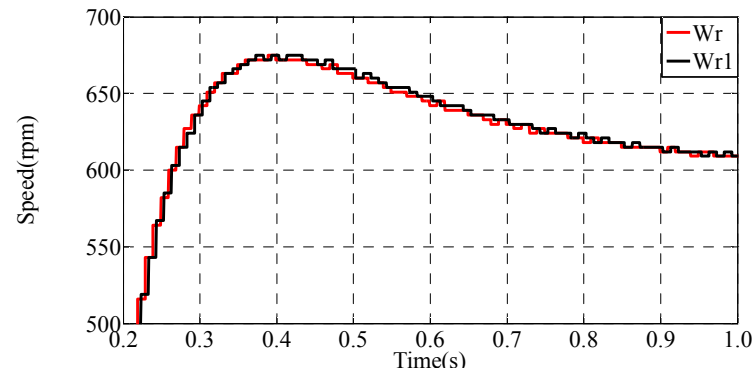

(c)

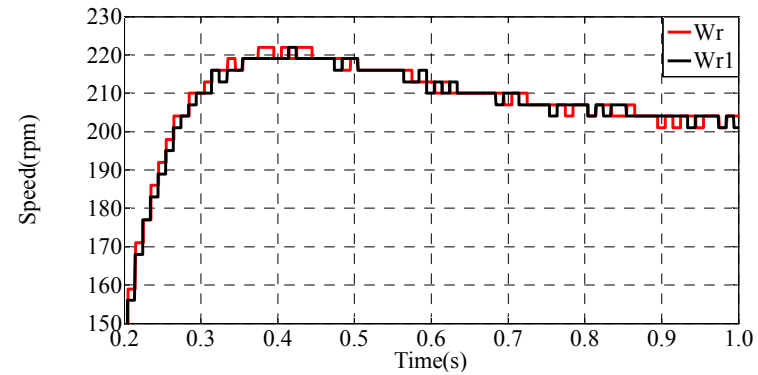

(d)

Fig. 5. Experimental results comparing motor speed responses of single motor and two motor operation at 200rpm, 600rpm and 1000rpm step speed commands (a) Overall response and Transient response at (b) $1000 \mathrm{rpm}$ (c)600rpm and (d)200rpm.

operation represented as motor $\mathrm{M}$ and with the FLI for two motor operations represented as motor 1, M1 and motor 2, M2. The speed responses for M, M1 and M2 are denoted as $\mathrm{Wr}, \mathrm{Wr} 1$ and $\mathrm{Wr} 2$ while the reference speed demand is denoted as $\mathrm{Wr}^{*}$ at the three different speeds. A close-up view of the responses during the transient period is shown in Fig. 5(b), 5(c) and 5(d) for 1000rpm, 600rpm and 200rpm, respectively. 


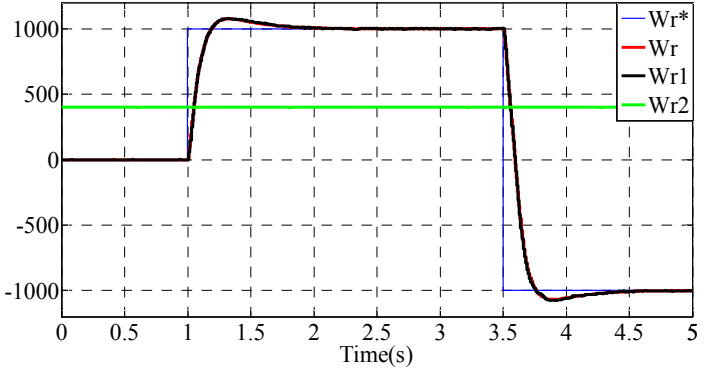

Fig. 6. Experiment results comparing motor speed responses of single motor and two motor operation during standstill, forward and reverse direction at 1000rpm speed operation.

By referring to all of the speed performances of the single motor operation, $\mathrm{Wr}$ and the speed response of M1 for the FLI system, Wr1, the results show almost identical performances with all three of the speed demand operations. However, the performance of the motor responses such as the rise time, settling time and percent overshoot are obtained respective to the PI controller performance. The accuracy of the speed response can be further improved by using a higher resolution encoder.

\section{B. Forward and reverse step speed commands}

Fig. 6 shows the step function demand applied from zero speed to $1000 \mathrm{rpm}$ in the forward and reverse directions.

Based on these results, the motor tracks the command speed with almost zero speed error during the steady state condition with similar settling times for both forward and reverse speed operations. Meanwhile, motor M2 operates at a fixed speed of 400rpm and does not effect of the speed changes for motor M1.

Fig. 7(a) shows the torque current, Iq for motor $M$ with the TLI. Meanwhile Fig. 7(b) shows the torque current, Iq for motor M1 and motor M2 with the FLI motor performances. The torque current reaches limiter $10 \mathrm{~A}$ set at the speed controller. The response shows an identical response time. However, a higher torque ripples are recorded for Iq1 and Iq2 which represent $\mathrm{M} 1$ and M2 for the FLI system in comparison with the torque current for a single motor, IqM for the TLI system. Iq1 experiences about $1.4 \mathrm{Nm}$ torque ripple and IqM experiences approximately $0.8 \mathrm{Nm}$ torque ripple.

\section{Operation under Load Condition}

The load rejection capabilities of the design are investigated when a nominal load disturbance is applied during a 1000rpm speed demand as shown in Fig. 8. The load disturbance operation is accomplished through a DC machine using load bank switches. The permanent magnet DC machine operates as a generator by connecting the armature terminals to the resistor bank. The external resistor of the DC machines is set to produce the rated current load at IM. The

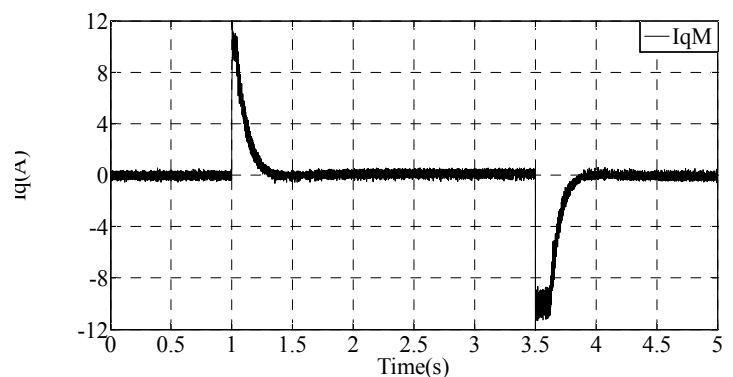

(a)

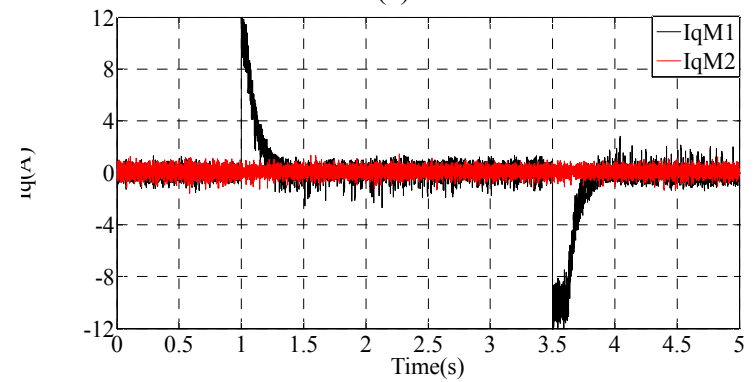

(b)

Fig. 7. Experimental result of torque current, Iq during standstill, forward and reverse direction at 1000rpm speed operation, (a) Torque current, IqM response for TLI (b) Torque current response IqM1 and IqM2 for FLI.

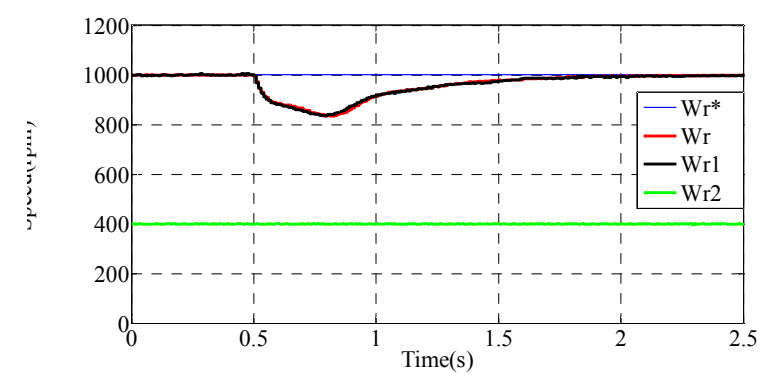

Fig. 8. Experiment results comparing motor speed responses of single motor and two motor operation during load disturbance rejection at $1000 \mathrm{rpm}$.

motor is operated at 1000rpm and suddenly a rated load disturbance is applied at $0.5 \mathrm{~s}$ for motor $\mathrm{M}$ with a TLI and motor M1 with a FLI. Similar performance can be seen on the speed drop and recovery time between the single motor operation using a TLI and motor M1 operation using a FLI. It can be seen that, the motor has same capability in terms of load disturbance rejection at the rated load. Meanwhile, motor M2 is in the unloaded condition which does not effect of the load disturbance in motor M1. This shows the independence of load disturbances in the case of two motor operation using a FLI system.

Fig. 9(a) shows the phase A current component for the single motor $\mathrm{M}$, denoted as IaM, and for motor M1, denoted as IaM1, for two motor operation. The results show similar characteristic when a rated load is applied at $0.5 \mathrm{~s}$ for both systems. Similar current amplitudes and periods can be seen for both motors conditions. Meanwhile, motor M2 which is running at the no load condition at 400rpm does not show 


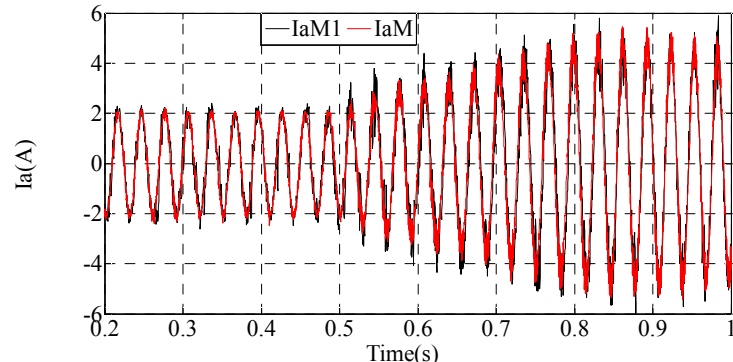

(a)

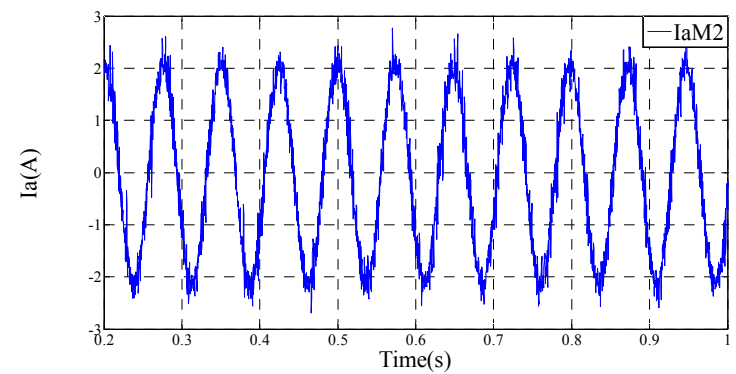

(b)

Fig. 9. Phase A current (a) Comparison between Ia for single motor, IaM and Ia for M1 motor, IaM1 (b) Ia current for M2, IaM2.

any effect when a load is applied to M1, as shown in Fig. 9(b)

\section{Motor Phase Current Comparison}

Fig. 10 depicts the analysis of the phase $\mathrm{C}$ current of the motors in the steady state condition under no load operation. Its shows a higher ripple for the phase $\mathrm{C}$ motor $\mathrm{M} 1$ when compared to the phase $\mathrm{C}$ motor $\mathrm{M}$ which connected to a TLI. Ten cycle current waveform are selected for the Fast Fourier Transform (FFT) analysis. In order to have a better view of the harmonics spectrum, the frequency is limited to the $100 \mathrm{~Hz}$ range and the magnitude is limited to $10 \%$ of the fundamental components. The results show a higher Total Harmonic Distortion (THD) at motor M1 when compared to the THD produced at motor $\mathrm{M}$ at $8.24 \%$ and $2.94 \%$, respectively, with similar speed operation. Similar fundamental currents are produced by motor $\mathrm{M}$ and motor M1 at 2.062Arms and 2.063Arms, respectively. The higher THD result for the FLI is due to the higher switching losses generated from the modulation method.

TABLE III shows a THD comparison for all of the phases between motor $\mathrm{M}$ and motor M1. Based on the THD results, all of the phases show a higher THD for motor M1 when compared to motor $\mathrm{M}$. There is no significant difference between the THD at phase $\mathrm{C}$ and the other phases.

Fig. 11 shows the phase $\mathrm{C}$ current at motor M2 by using a FLI which operated at 400rpm. The fundamental current is 1.94 Arms and the THD is $4.93 \%$.

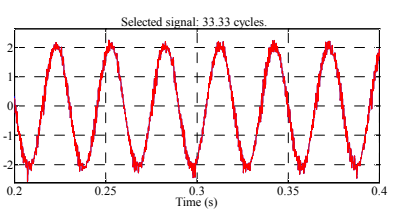

(a)

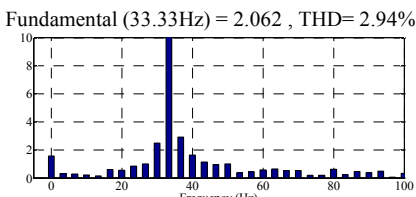

(b)

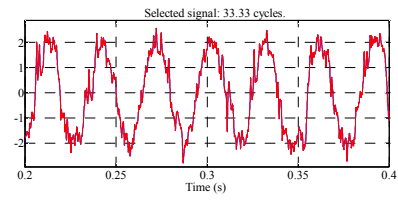

(c)

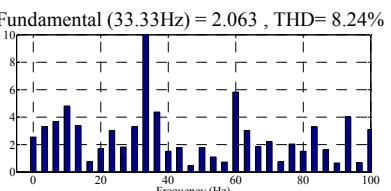

(d)

Fig. 10. Phase C current component of the induction motor; (a) Current waveform for motor M, (b) Harmonic spectrum for motor M, (c) Current waveform for motor M1 (d) Harmonic spectrum for motor M1.

TABLE III

THD COMPARISON BETWEEN MOTOR M AND MOTOR M1

\begin{tabular}{|l|l|l|}
\hline \multicolumn{1}{|c|}{ Phase } & Motor $\mathbf{M}$ & Motor M1 \\
\hline A & RMS $=2.049$ & RMS $=2.046 \mathrm{~A}$ \\
& $\mathrm{THD}=2.8 \%$ & $\mathrm{THD}=6.72 \%$ \\
\hline $\mathrm{B}$ & $\mathrm{RMS}=2.1 \mathrm{~A}$ & $\mathrm{RMS}=2.103 \mathrm{~A}$ \\
& $\mathrm{THD}=3.31 \%$ & $\mathrm{THD}=8.02 \%$ \\
\hline $\mathrm{C}$ & $\mathrm{RMS}=2.062 \mathrm{~A}$ & $\mathrm{RMS}=2.063 \mathrm{~A}$ \\
& $\mathrm{THD}=2.94 \%$ & $\mathrm{THD}=8.24 \%$ \\
\hline
\end{tabular}

Selected signal: 13.33 cycles. FFT window (in red): 10 cycles

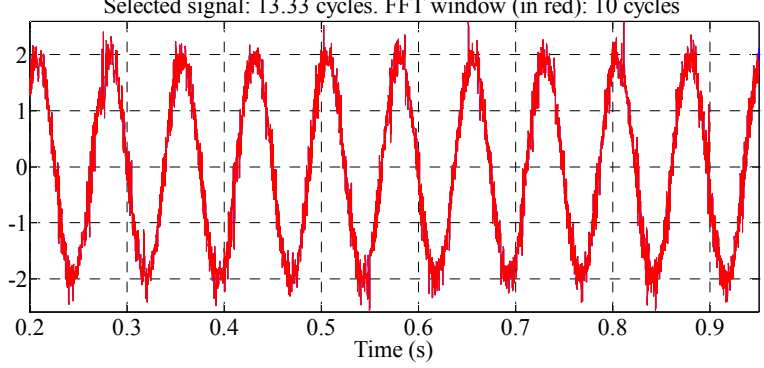

(a)

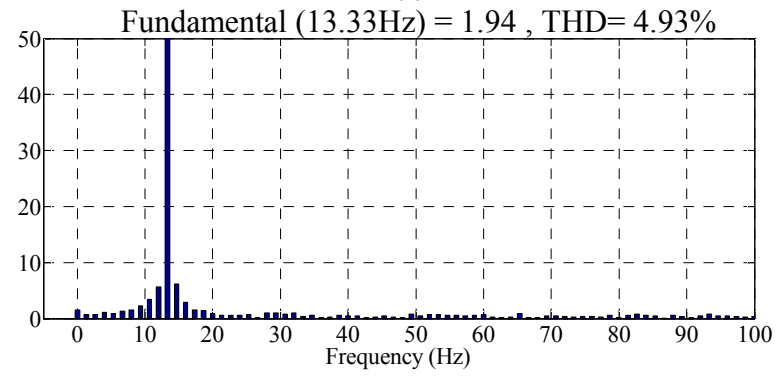

(b)

Fig. 11. Phase $\mathrm{C}$ current component of the induction motor M2 using FLI; (a) Current waveform (b) Harmonic spectrum.

\section{E. Inverter Leg Current Comparison}

Fig. 12(a) shows the current waveform at leg $\mathrm{C}$ of the common leg for the FLI in comparison to the current 


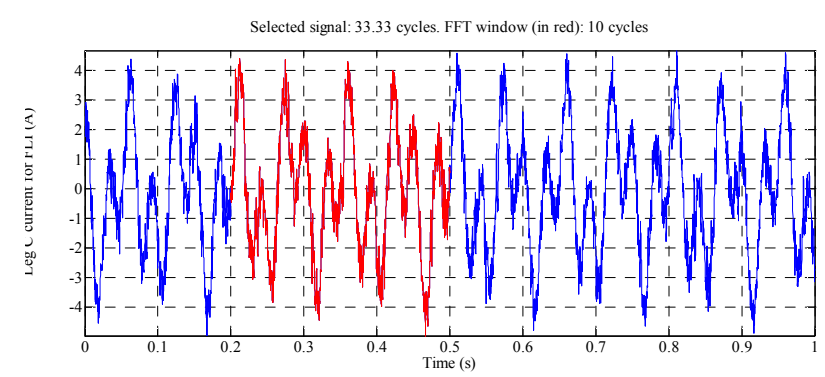

(a)

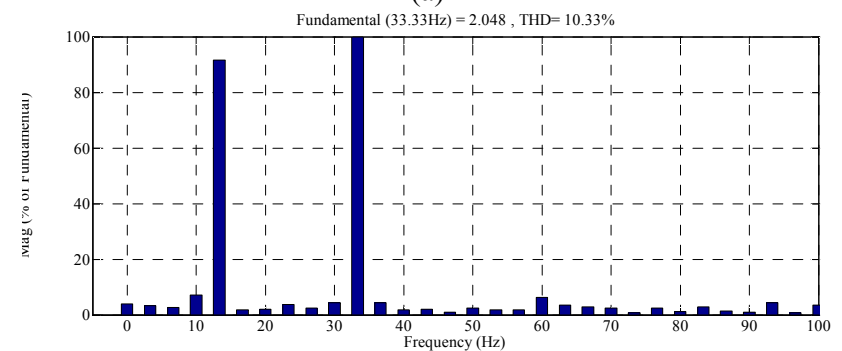

(b)

Fig. 12. Common leg C current at FLI inverter; (a) Current waveform (b) THD analysis.

waveform in the TLI in Fig. 10. This command leg experiences a higher current compare to the other leg of the FLI or TLI. For this FFT analysis, the motor M1 signal is used as the base quantity. The FFT window is set at $0.2 \mathrm{~s}$ for 10 cycles in the range of the fundamental frequency at $33.33 \mathrm{~Hz}$. The current spectrum analysis result is depicted in Fig. 12(b). Based on this result, two current components exist at $33.33 \mathrm{~Hz}$ and $13.33 \mathrm{~Hz}$ resulting from the steady state speed operation. The fundamental current for motor M1 at $33.33 \mathrm{~Hz}$ is 2.048Arms and second current component for motor M2 at $13.33 \mathrm{~Hz}$ produces $91.6 \%$ of the fundamental current magnitude. The total current at the common leg is higher when compared to the TLI or the other legs in the FLI.

\section{CONCLUSION}

This paper presents an individual motor performance comparison between TLI and FLI systems. The FLI system configuration gives advantages in term of reducing power transistor components, since it only uses one controller and one power source. The speed performance of the independent control of two motors using the FLI is comparable to TLI systems in following various step speed demand operations, forward/reverse operations and load disturbance rejection capability under the speed limitation of the FLI. However, the torque current performance shows a higher ripple for the motors in the FLI system when compared to the single motor with the TLI system. The harmonic content with the FLI is three times higher when compared with the conventional TLI. The higher THD current at the motor using the FLI is a result of its modulation technique. In addition, the common leg in the FLI configuration experienced a higher amplitude current due to the sum of the two phase current components at different frequencies of speed operation. Thus this effect can be minimized by alternating the speed and load operations.

\section{ACKNOWLEDGEMENT}

The authors would like to acknowledge their gratitude to the Faculty of Electrical Engineering, Universiti Teknikal Malaysia Melaka, Durian Tunggal, Melaka, Malaysia, for providing the resources and support for this study.

\section{REFERENCES}

[1] Y. Ohama, K. Oka, and K. Matsuse, "Characteristic of independent two induction motor drives fed by a five-leg inverter," in International Conference on Electrical Machines and Systems, pp. 1-4, 2009.

[2] R. Omata, K. Oka, A. Furuya, S. Matsumoto, Y. Nozawa, and K. Matsuse, "An Improved Performance of Five-Leg Inverter in Two Induction Motor Drives," in Power Electronics and Motion Control (IPEMC) Conference, pp. $1-5,2006$

[3] S. N. Vukosavic, M. Jones, D. Dujic, and E. Levi, "An improved PWM method for a five-leg inverter supplying two three-phase motors," in IEEE International Symposium on Industrial Electronics (ISIE), pp. 160-165, 2008.

[4] M. Jones, D. Dujic, and E. Levi, "A performance comparison of PWM techniques for five-leg VSIs supplying two-motor drives," in Industrial Electronics Conference (IECON), pp. 508-513, 2008.

[5] M. Jones, D. Dujic, E. Levi, M. Bebic, and B. Jeftenic, "A two-motor centre-driven winder drive fed by a five-leg voltage source inverter," in Power Electronics and Applications Conference, pp. 1-10, 2007.

[6] P. Delarue, A. Bouscayrol, and B. Francois, "Control implementation of a five-leg voltage-source-inverter supplying two three-phase induction machines," in IEEE International Electric Machines and Drives Conference (IEMDC), pp. 1909-1915, 2003.

[7] N. Kezuka, K. Oka, and K. Matsuse, "Characteristics of independent two induction motor drives fed by a four-leg inverter," in Energy Conversion Congress and Exposition (ECCE, pp. 2114-2120, 2010.

[8] A. Furuya, K. Oka, and K. Matsuse, "A characteristic analysis of four-leg inverter in two AC motor drives with independent vector control," in International Conference on Electrical Machines and Systems (ICEMS), pp. 619-624, 2007.

[9] A. Bouscayrol, S. Siala, M. Pietrzak-David, and B. deFornel, "Four-legged PWM inverters feeding two induction motors for a vehicle drive application," in Power Electronics and Variable-Speed Drives Conference, pp. 700-705, 1994.

[10] E. Ledezma, B. McGrath, A. Munoz, and T. A. Lipo, "Dual AC-drive system with a reduced switch count," IEEE Trans. Ind. Appl., Vol. 37, No. 5, pp. 1325-1333, Sep./Oct. 2001.

[11] M. Jones, S. N. Vukosavic, D. Dujic, E. Levi, and P. Wright, "Five-leg inverter PWM technique for reduced switch count two-motor constant power applications," IET on Electric Power Applications, Vol. 2, No. 5, pp. 275-287, Sep. 2008.

[12] K. Oka, Y. Nozawa, R. Omata, K. Suzuki, A. Furuya, and K. Matsuse, "Characteristic comparison between five-leg inverter and nine-switch inverter," in Power Conversion Conference (PCC), pp. 279-283, 2007. 
[13] T. Kominami and Y. Fujimoto, "Inverter with reduced switching-device count for independent AC motor control," in Industrial Electronics Society Conference (IECON), pp. 1559-1564, 2007.

[14] M. H. N. Talib, Z. Ibrahim, N. Abdul Rahim, and N. Mohd Yaakop, "Development of combined vector and direct torque control methods for independent two induction motor drives," in Power Engineering and Optimization Conference (PEOCO), pp. 78-83, 2012.

[15] M. H. N. Talib, Z. Ibrahim, N. A. Rahim, and A. S. A. Hasim, "Analysis on speed characteristics of five leg inverter for different carrier based PWM scheme," in Power Engineering and Optimization Conference (PEOCO) , pp. 96-101, 2012.

[16] N. M. Yaakop, Z. Ibrahim, M. Sulaiman, and M. H. N. Talib, "Speed performance of SVPWM direct torque control for five leg inverter served dual three-phase induction motor," in Power Engineering and Optimization Conference (PEOCO), pp. 323-328, 2012.

[17] A. Hara, H. Enokijima, and K. Matsuse, "Independent vector control of two induction motors fed by a five-leg inverter with space vector modulation," in Industry Applications Society Annual Meeting (IAS), pp. 1-8, 2011.

[18] M. Jones, D. Dujic, E. Levi, A. Batako, and O. Mgaloblishvili, "A Novel Five-leg Inverter PWM Technique for Two-Motor Centre-Driven Winders," in International Electric Machines \& Drives Conference (IEMDC), pp. 254-259, 2007.

[19] K. Matsuse, H. Kawai, Y. Kouno, and J. Oikawa, "Characteristics of speed sensorless vector controlled dual induction motor drive connected in parallel fed by a single inverter," IEEE Trans. Ind. Appl., Vol. 40, No. 1, pp. 153-161, Jan./Feb. 2004.

[20] K. Oka, Y. Ohama, H. Kubota, I. Miki, and K. Matsuse, "Characteristic of independent two AC motor drives fed by a five-leg inverter," in Industry Applications Society Annual Meeting (IAS), pp. 1-8, 2009.

[21] D. Dujic, M. Jones, E. Levi, and S. N. Vukosavic, "A two-motor centre-driven winder drive with a reduced switch count," in IEEE Industrial Electronics Conference, pp. 1106-1111, 2008.

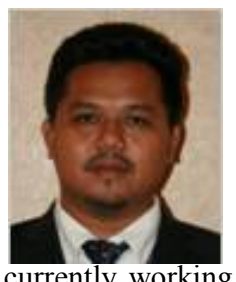

Md Hairul Nizam Talib was born in Malaysia, in 1976. He received his B.S. in Electrical Engineering from the Universiti Teknologi Malaysia (UTM), Johor Bahru, Johor, Malaysia, in 1999, and his M.S. in Electrical Engineering from the University of Nottingham, Nottingham, UK, in 2005. He is currently working towards his Ph.D. at the Universiti Teknikal Malaysia Melaka (UTeM), Durian Tunggal, Melaka, Malaysia. He has been a lecturer at UTeM since 2002. His current research interests include power electronics, fuzzy logic control and motor drives.

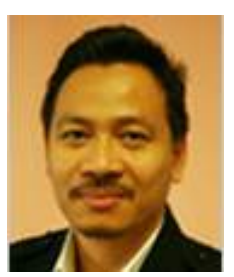

Zulkifilie Ibrahim was born in Malaysia, in 1966. He received his B.S. in Engineering from the University of Technology (UTM), Johor Bahru, Johor, Malaysia, in 1989, and his Ph.D. from the Liverpool John Moores University, Liverpool, UK, in 1999. He has been an Associate Professor at the Universiti Teknikal Malaysia Melaka (UTeM), Durian Tunggal, Melaka, Malaysia, since 2006. His current research interests include power electronics, fuzzy logic control, embedded system design and electric motor drives.

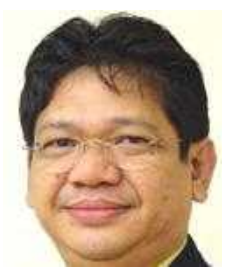

Nasrudin Abd. Rahim was born in Johor, Malaysia, in 1960. He received his B.S. (with Honors) and M.S. from the University of Strathclyde, Glasgow, U.K., and his Ph.D. from Heriot-Watt University, Edinburgh, U.K., in 1995. He is currently a Professor at the University of Malaya, Kuala Lumpur, Malaysia, where he is also the Director of the University of Malaya Power Energy Dedicated Advanced Centre (UMPEDAC). At present he is an Adjunct Professor at King Abdulaziz University, Jeddah, Saudi Arabia. Professor Rahim is a Senior Member of the IEEE, a Fellow of the Institution of Engineering and Technology, U.K., and a Fellow of the Academy of Sciences Malaysia. He is also a Chartered Engineer. His current research interests include power electronics, real-time control systems, electrical drives and renewable energy systems.

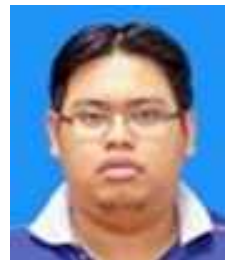

Ahmad Shukri Abu Hasim received his Diploma, B.S. and M.S. in Electrical Engineering majoring in Power from the Universiti Teknologi Mara, Shah Alam, Malaysia, in 2000, 2004 and 2008, respectively. He is a Lecturer at the Universiti Pertahanan Nasional, Kuala Lumpur, Malaysia, and is currently pursuing his Ph.D. at the Universiti Teknikal Malaysia Melaka (UTeM), Durian Tunggal, Melaka, Malaysia. His current research interest include power electronic and drive systems. 